\title{
The value of high adherence to tamoxifen in women with breast cancer: a community- based cohort study
}

\author{
C McCowan*,1, S Wang ${ }^{2}$, A M Thompson ${ }^{3}$, B Makubate ${ }^{4}$ and D J Petrie ${ }^{5}$
}

${ }^{1}$ Robertson Centre for Biostatistics, Institute of Health and Wellbeing, College of Medical, Veterinary and Life Sciences, University of Glasgow, Boyd Orr Building, Level 11, Scotland G12 80Q, UK; ${ }^{2}$ Centre for Health Policy, Imperial College Business School, London, UK; ${ }^{3}$ Dundee Cancer Centre, Ninewells Hospital and Medical School, University of Dundee, Scotland, UK; ${ }^{4}$ College of Science, Botswana International University of Science and Technology, P/Bag B041, Gaborone, Botswana and ${ }^{5}$ Centre for Health Policy, Programs and Economics, Melbourne School of Population and Global Health, University of Melbourne, Melbourne, Victoria, Australia

Background: Low adherence to adjuvant tamoxifen is associated with worse health outcomes but little is known about the costeffectiveness of high adherence.

Methods: We conducted an economic evaluation using data for all women with incident breast cancer between 1993 and 2000 who were subsequently prescribed tamoxifen in the Tayside region of Scotland. Patient-level, lifetime Markov models evaluated the impact of high vs low adherence to tamoxifen using linked prescribing, cancer registry, clinical cancer audit, hospital discharge and death records. Direct medical costs were estimated for each patient and quality-of-life weights were assigned. Recurrence information was collected by case note review and adherence calculated from prescribing records with low adherence classed below $80 \%$

Results: A total of 354 (28\%) patients had a recorded recurrence and 504 (39\%) died. Four hundred and seventy-five (38\%) patients had low adherence over the treatment period, which was associated with reduced time to recurrence of $52 \%(P<0.001)$. Time to other cause mortality was also reduced by $23 \%(P=0.055)$ but this was not statistically significant. For an average patient over her lifetime, low adherence was associated with a loss of 1.43 (95\% Cl: 1.15-1.71) discounted life years or 1.12 (95\% Cl: 0.91-1.34) discounted quality-adjusted life years (QALYs) and increased discounted medical costs of $£ 5970$ (95\% Cl: $£ 4644-£ 7372)$. Assuming a willingness to pay threshold of $£ 25000$ per $Q A L Y$, the expected value of changing a patient from low to high adherence is $£ 33897$ (95\% Cl: £28 322-£39652).

Conclusion: Patients with low adherence have shorter time to recurrence, increased medical costs and worse quality of life. Interventions that encourage patients to continue taking their treatment on a daily basis for the recommended 5-year period may be highly cost-effective.

Randomised clinical trials in early breast cancer have shown that tamoxifen reduces recurrence and mortality in women with oestrogen receptor (ER)- or progesterone receptor (PR)-positive cancers and it is recommended for a 5-year period (Scottish Intercollegiate Guideline Network Guidelines, 2005; Early Breast
Cancer Trialists' Collaborative Group, 2011). However, there is a growing evidence that the efficacy of tamoxifen in recurrence and mortality reduction is contingent upon patient adherence, that is, 'the extent to which a patient's behaviour... coincides with medical or health advice' (McDonald et al, 2002).

*Correspondence: Dr C McCowan; E-mail: Colin.McCowan@glasgow.ac.uk

Received 23 April 2013; revised 12 July 2013; accepted 21 July 2013; published online 15 August 2013

(C) 2013 Cancer Research UK. All rights reserved 0007-0920/13 
Studies have reported that one-third to a half of women do not complete the recommended 5-year tamoxifen treatment and that this is associated with an increased mortality risk (Barron et al, 2007; Ma et al, 2008; McCowan et al, 2008; Owusu et al, 2008; Yood et al, 2008; Narod, 2010; van Herk-Sukel et al, 2010; Hershman et al, 2011; Murphy et al, 2012; Hadji et al, 2013; Huiart et al, 2013; Makubate et al, 2013). Other work has shown that $19-28 \%$ of women prescribed adjuvant tamoxifen in the community miss at least one out of five daily doses putting adherence below $80 \%$, a level also associated with increased risk of all-cause mortality (Patridge et al, 2003; McCowan et al, 2008; Dezentje et al, 2010; Hershman et al, 2010, 2011; Makubate et al, 2013).

Economic analyses of adjuvant tamoxifen have shown benefits, an early study using trial data reported users gained 0.4 qualityadjusted life years (QALYs) over controls with an incremental cost per QALY gained of AUS\$1365 (Glasziou and Haas, 1994). A more recent study using a community-based observational cohort of women with breast cancer in Korea reported that tamoxifen was cost-effective for patients with stage I or II ER- or PR-positive cancers and for all patients with stage III disease (Yang et al, 2010). However, we were unable to identify any previous study that has examined the impact of patient adherence on the cost-effectiveness of tamoxifen therapy for early breast cancer. In another field, improving adherence to statins would enhance cost-effectiveness, with a projected decrease in incremental cost per QALY gained from $€ 35000$ to $€ 26000$ for complete adherence (Greving et al, 2011).

It is plausible that along with a negative impact on health outcomes, low adherence to adjuvant tamoxifen may also induce higher health-care costs. Patients with low adherence may receive less clinical benefit with lower quality of life and require more long-term health services because of disease recurrence. An economic evaluation relating to the value of adherence to adjuvant tamoxifen is required to inform clinical and policy decisions on designing and evaluating interventions, which improve adherence.

The aims of this study were to investigate patient adherence to tamoxifen in a geographically defined population of women in Tayside, Scotland; to assess the extent to which low adherence affects recurrence, mortality and medical costs after adjusting for important clinical and demographic factors; and to compare the cost-effectiveness of tamoxifen therapy between patients with high and low adherence.

\section{MATERIALS AND METHODS}

Women resident in Tayside, UK, diagnosed and treated for breast cancer between January 1993 and December 2008 were identified using previously described methods (McCowan et al, 2008; Makubate et al, 2013). Only those women resident in Tayside for the entire period of the study, or until death, were included. Community dispensed prescribing, hospital discharge records, cancer registry, cancer audit and General Registrar's Office death certificates were extracted, record-linked and anonymised for each patient.

Patients were excluded from the study population if there was no known cause of death (7), no record of surgical treatment for cancer (569), had received endocrine therapy for more than 6 months before their diagnosis (104), or were known to be enrolled on endocrine trials (52).

Tamoxifen has been used throughout the study period with aromatase inhibitors (AIs) used as adjuvant endocrine therapy since 2001. The decision on which therapy to use is determined by menopausal status, ER/PR status and risk of recurrence. From dispensed prescribing data, 836 (25\%) patients received no adjuvant therapy, 2254 (68\%) patients were initially prescribed tamoxifen and 249 (7\%) were prescribed an AI. Because of a short median follow-up for patients on AIs and to also remove the possibility of selection bias, only patients on tamoxifen diagnosed by the end of December 2000 who did not switch to AIs were included in the analysis; this reduced the sample to 1301 patients.

A further four patients who recurred or died within 60 days of diagnosis and 34 patients who received their first tamoxifen prescription later than 1 year post diagnosis were also excluded.

Adherence. Each tamoxifen prescription was examined and the number of days covered obtained from the number of dispensed tablets and the prescribed daily dose. When tablets or dose were unavailable for a prescription (1.9\% of cases) they were imputed according to tablets or dose from the patient's subsequent prescriptions if available or otherwise previous prescriptions. The expected duration of adjuvant therapy was calculated from the number of days elapsed since diagnosis or the first prescription, if earlier, until either recurrence or death, end of the sample period, or the completion of the standard 5-year therapy. Patients close to recurrence or death may be less likely to adhere, thus patients' adherence for the last 60 days before recurrence/death was not included. The absolute adherence for each patient was calculated as the ratio of the total coverage for all the prescriptions relative to the expected duration. Based on the existing literature, low adherence was defined as less than $80 \%$ (Murthy et al, 2002; Patridge et al, 2003; McCowan et al, 2008; Makubate et al, 2013). In the current paper, low adherence combined those non-persistent with those persistent but not adherent.

Patient and cancer characteristics. Date of diagnosis and age at the time of diagnosis were recorded from clinical cancer records. Scottish Index of Multiple Deprivation quintiles (ranging from 1 to 5 for most to least deprived) were allocated based on each patient's full postcode and provided a proxy for socioeconomic characteristics (Scottish Government, 2012). A Charlson's Index for co-morbidity was derived from hospital discharge records using standard procedures (Deyo et al, 1992; Sundararajan et al, 2004). The tumour characteristics on presentation were determined using TNM categories (tumour size, nodal status and metastases), pathological grading and ER status. The patients' disease progress was observed using the information on date of death, cause of death, date of recurrence and type of recurrence (e.g., local recurrence, axillary recurrence and distance recurrence).

Markov model. To value the benefit of high $v s$ low adherence to tamoxifen, a simulated patient-level Markov model was developed to predict patients' lifetime disease progress and lifetime costs. Rather than using equal length cycles, the model tracks disease progression of the heterogeneous patient population by sampling the time to next event and costs from patient-specific distributions based on the Tayside sample.

Model structure. The Markov model portrays disease progression from the point of initial diagnosis to death (Figure 1). Patients entering the simulation model were defined with the unique attributes of each patient and their cancer but were assumed to be diagnosed in 2000, and to initiate and continue adjuvant tamoxifen therapy for 5 years or until they recurred or died from other causes. Each patient was modelled assuming both high $(\geqslant 80 \%)$ and low adherence $(<80 \%)$.

In the first stage of the model, diagnosed patients were subject to patient-specific risks of recurrence or other-cause mortality based on their characteristics. Those predicted to recur then entered the second stage and were subject to risks of breast cancer mortality and other-cause mortality. Within each stage, the model sampled the time to different events from the patient-specific distributions to determine whether the patient makes transitions between health states. Based on existing literature, patients were assumed to be at risk of breast cancer events at least for 15 years after diagnosis 


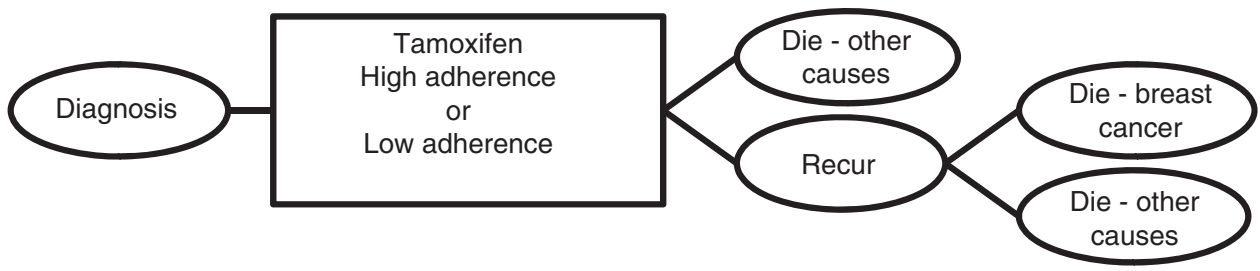

Figure 1. The Markov model for disease progression of breast cancer.

(Delea et al, 2007). All patients were also assumed to die from other causes at age 100 years if no event was predicted to occur before then. Direct medical costs were also derived by sampling from patient-specific cost distributions, which were based on their initial characteristics and current health state.

\section{Estimating model parameters}

Survival analysis. The simulation of the time to next event involved fitting the sample data to parametric survival-time models and then generating and sampling from the distribution of time to event for each patient. Estimations were conducted for three events separately: diagnosis to recurrence, recurrence to breast cancer mortality and diagnosis to recurrence-free mortality.

In order to predict event time, an accelerated failure time model (AFT model) is adopted, which assumes that the effect of a variate is to multiply the predicted event time by a constant. For each outcome, parametric survival and frailty distributions were fitted and results reported for the model preferred by the AIC selection criteria (Burnham and Anderson, 2004). The parametric survival distributions fitted included exponential, Weibull, Gompertz, lognormal, log-logistic and generalised gamma models, and the frailty distributions included no frailty, gamma and inverse Gaussian models. Because of small numbers, we assumed that other-cause mortality was not influenced by recurrence so the time from recurrence to other-cause death was simulated using the predicted time to recurrence-free mortality (minus time to recurrence).

Whether patients are adherent is based on a number of observable and unobservable characteristics. We included a propensity score within the analysis to allow for possible selection effects based on observed demographic and clinical characteristics (Indurkhya et al, 2006). A propensity score was created using a logistic regression model for a patient having low adherence to tamoxifen and fitted in the model as a linear score.

There were 103 patients who had breast cancer as a cause of death but no recorded recurrence information with $77 \%$ of these patients diagnosed within the first three sample years (i.e., 1993-1995). To reduce possible bias and account for uncertainty, our analyses used the Multivariate Imputation by Chained Equations method of multiple imputation with five replications of imputed data based on when recurrence occurred between diagnosis and breast cancer death for other patients (Van Buuren et al, 1999; Royston, 2004).

QALY. Quality-of-life weights for each health state were drawn from a study of 361 Swedish breast cancer patients in different disease states using preference-based measures (Lidgren et al, 2007). The utility value for primary breast cancer (mean: 0.696, 95\% CI: 0.634-0.747) was assigned for the first year after diagnosis, after which the mean of utility value increased to 0.779 (95\% CI: $0.745-0.811$ ). Once patients recurred, they were assigned the utility for distant recurrence (mean: 0.685, 95\% CI: 0.620-0.735) until death. As individual data were not available, we employed the mean and 95\% CI to determine the best fitting beta distributions, from which QALYs were sampled for each simulated patient.
Direct medical costs. Direct medical costs for breast cancer and other conditions were estimated using the information on community dispensing and general/acute hospital admissions within the 5-year period after diagnosis. Dispensing was complete over the entire period for specified British National Formulary sections including endocrine therapy, with missing data for some other prescriptions during the periods between April 1997 to March 2000 and January 2002 to December2004.

Unit costs of community dispensing and in-patient hospital admissions were obtained from the Prescription Cost Analysis and 2007/08 Scottish Health Service Costs (ISD Scotland, Scottish Government, 2012a,b). Costs of the most commonly prescribed medication for tamoxifen prescriptions (TAMOXIFEN CIT_TAB 20 MG: $£ 0.07$ per quantity) and the average cost among all British National Formulary sections for other prescriptions ( $£ 11.67$ per dispensed item) were used. In-patient costs were calculated by specialty using costs per case and average length of stay reported for NHS Tayside.

Costs of tamoxifen were estimated for high- and low-adherence patients using the average of adherence within each group, $94.5 \%$ and $54.9 \%$, respectively. Patients were assumed to complete 5 years of therapy unless they recurred or died earlier. Costs of other prescriptions and in-patient admissions were estimated for each follow-up year and then modelled using regression methods.

Patient's costs were estimated using a two-part model: (1) a logistic regression for whether patients had any costs; (2) a least squares regression for the log of costs for patient-years with at least some costs. Regressions were based on uncensored patient-years up to 5 years post follow-up. Missing dispensing data were included but controlled for based on the proportion of missing calendar months within each particular follow-up year. In terms of the Markov model, the distribution of costs post 5 years follow-up were assumed to be equivalent to the costs within the 2- to 5-year follow-up period.

Estimating the value of high vs low adherence. Outcomes and costs of tamoxifen between high- and low-adherence patients are sampled from the distributions based on the regressions of survival time and medical costs, which are used to estimate lifetime QALYs and costs for each patient. The simulation was programmed using @Risk version 5.7 with 5000 iterations (Palisade. @Risk 5.7. 2009 Ithaca NY: Palisade Corporation). Future costs and benefits were discounted at the annual rate of $3.5 \%$, based on the recommendations of the UK Treasury (National Institute for Health and Clinical Excellence, 2011).

A cost-effectiveness type analysis was conducted to evaluate the economic consequences of a patient choosing high vs low adherence to her tamoxifen dispensing, in terms of costs and QALYs gained. The Monte Carlo simulation was used to estimate difference in lifetime cost between high and low adherence (incremental costs) and the difference in lifetime QALYs between the two groups (incremental QALYs). To evaluate the expected value of changing a patient from low adherence to high adherence, we adopted a willingness to pay threshold of $£ 25000$ per QALY (approximately the NICE threshold for recommended adoption of new products) and then the value or net monetary benefit (NMB) 
was calculated as $£ 25000$ per QALY times the difference in QALYs minus the differences in cost (Appleby et al, 2007). When generating the patient disease pathways and costs, a probability sensitivity analysis was included where the uncertainty in model parameters estimated and QALYs were also taken into account such that the confidence intervals generated reflect this uncertainty.

Sensitivity analysis. In addition to the probability sensitivity analysis, the robustness of the baseline results was also assessed by a sensitivity analysis where assumptions on both costs and health effects were adjusted. The baseline case allowed annual costs of in-patients and other dispensing to differ because of high or low adherence. In fact, patients with low adherence in our sample were estimated to have a lower probability of incurring costs but once they did incur costs, the cost estimates were significantly higher. In the sensitivity analysis, we considered that these estimates may be a correlated behavioural response, aversion to seeking medical care, rather than the actual impact of low adherence, and examined a scenario where low adherence did not influence costs other than through recurrence or early death. Following NICE guidelines, the impact of varying the duration of the outcomes was also examined by reducing the discount rate for health outcomes from 3.5 to $1.5 \%$.

In addition, our data suggested adherence to medications, in general, diminishes the longer a patient is from initiating medication, thus those who do not recur or die may have lower average adherence levels than those who recurred or died early. Thus, a relative adherence index was also created using the average cumulative adherence index for all patients who had been observed at the same follow-up year for a robustness check. Only the results for absolute adherence are reported given relative adherence produced similar results.

\section{RESULTS}

A total of 1263 women prescribed adjuvant tamoxifen survived more than 60 days after diagnosis. There were a total of 525 (42\%) deaths during the study and 354 (28\%) recurrences. Of the women with a recurrence, $306(86 \%)$ died because of breast cancer and 21 (6\%) died from other causes. There were 198 (16\%) deaths from other causes in women without recurrence.

Patient characteristics and adherence. During the period from diagnosis to recurrence or death, 475 (38\%) patients had low adherence to medication, missing at least one tablet of every five over the course of their therapy. The average monthly adherence index for our patients reduced over time from diagnosis from $85 \%$ (s.d. $=0.44)$ at 12 months to $81 \%($ s.d. $=0.48)$ at 36 months and, finally, $75 \%$ (s.d. $=0.43$ ) at 60 months.

The demographic and clinical characteristics of patients at diagnosis are shown in Table 1. A logistic regression model reported patients were more likely to have low adherence if they were younger women $(\mathrm{OR}=0.26,80+v s<60$ years, 95\% CI: $0.15-0.45, P<0.001)$, had higher tumour stage ( $\mathrm{OR}=1.72$, stage 3 or stage $4 v s$ stage 1 or $2,95 \% \mathrm{CI}$ : $1.10-2.67, P=0.016)$ or had ER-negative status $(\mathrm{OR}=0.49, \mathrm{ER}+$ ve $v$ s $\mathrm{ER}-\mathrm{ve}, 95 \% \mathrm{CI}$ : $0.32-0.74, P<0.001)$ after controlling for menopausal status, social class, co-morbidity and other clinical characteristics.

Accelerated failure-time models for recurrence and death. For the 475 patients with low adherence to medication, 127 (27\%) had a recurrence and $63(13 \%)$ died before recurrence over the study period. For those with high adherence, 197 (25\%) had a recurrence and $135(17 \%)$ died before recurrence. Survival time from diagnosis to recurrence, diagnosis to recurrence-free death and

\begin{tabular}{|c|c|c|c|c|c|}
\hline \multirow{3}{*}{ Age group (years) } & \multicolumn{4}{|c|}{ Adherence } & \multirow{3}{*}{\begin{tabular}{|l|}
$\boldsymbol{P}$-value \\
$<0.001$
\end{tabular}} \\
\hline & \multicolumn{2}{|c|}{$\begin{array}{l}\text { High }(\geqslant 80 \%) \\
(N=788), \%\end{array}$} & \multicolumn{2}{|c|}{$\begin{array}{l}\text { Low }(<80 \%) \\
(\mathbf{N}=475), \%\end{array}$} & \\
\hline & & & & & \\
\hline$<60$ & 316 & (40) & 289 & (61) & \\
\hline 60-69 & 214 & (27) & 98 & (21) & \\
\hline 70-79 & 178 & (23) & 69 & (15) & \\
\hline $80+$ & 80 & (10) & 19 & (4) & \\
\hline Menopausal & & & & & 0.005 \\
\hline Pre/Peri & 64 & (8) & 59 & (12) & \\
\hline Post & 262 & (33) & 135 & (28) & \\
\hline Unknown & 462 & (59) & 281 & (59) & \\
\hline SIMD quintile & & & & & 0.674 \\
\hline 1-2 (Deprived) & 228 & (29) & 132 & (28) & \\
\hline 3-5 (Affluent) & 548 & (70) & 335 & (71) & \\
\hline Unknown & 12 & (2) & 8 & (2) & \\
\hline Charlson's index & & & & & 0.527 \\
\hline 0 & 340 & (43) & 216 & (45) & \\
\hline $1-2$ & 268 & (34) & 147 & (31) & \\
\hline $3+$ & 180 & (23) & 112 & (24) & \\
\hline Tumour stage & & & & & 0.014 \\
\hline $1-2$ & 424 & (54) & 263 & (55) & \\
\hline $3-4$ & 56 & (7) & 57 & (12) & \\
\hline Unknown & 308 & (39) & 155 & (33) & \\
\hline Axillary nodes & & & & & 0.357 \\
\hline 1 & 464 & (59) & 311 & (65) & \\
\hline $2-3$ & 78 & (10) & 62 & (13) & \\
\hline Unknown & 246 & (31) & 102 & (21) & \\
\hline Metastases & & & & & 0.570 \\
\hline No & 545 & (69) & 371 & (78) & \\
\hline Yes & 10 & (1) & 7 & (1) & \\
\hline Unknown & 233 & (30) & 97 & (20) & \\
\hline Tumour grade & & & & & 0.082 \\
\hline $1-2$ & 340 & (43) & 208 & (44) & \\
\hline 3 & 173 & (22) & 136 & (29) & \\
\hline Unknown & 275 & (35) & 131 & (28) & \\
\hline Oestrogen receptor status & & & & & $<0.001$ \\
\hline Negative & 55 & (7) & 69 & (15) & \\
\hline Positive & 389 & (49) & 239 & (50) & \\
\hline Unknown & 344 & (44) & 167 & (35) & \\
\hline
\end{tabular}

recurrence to breast cancer death were calculated from a lognormal regression (see Table 2).

The presence of involved axillary lymph nodes $(P<0.001)$ and higher tumour grade $(P=0.001)$ were each associated with shorter time to recurrence; age $(P<0.001)$ and social class $(P=0.020)$ with shorter time to recurrence-free death; and age $(P=0.007)$ with shorter time from recurrence to breast cancer death after allowing for other factors. For patients with low adherence to tamoxifen, the expected time until recurrence reduced significantly by $52.38 \%$ $(P<0.001)$, but there was no significant effect on time to other cause death or breast cancer death after recurrence.

Medical costs. Patients diagnosed at an older age $(P<0.001)$, living in a deprived area $(P<0.001)$ or with clinical metastases $(P=0.022)$ were more likely to have costs within their subsequent follow-up years after adjusting for other factors (Table 3 ). Once 
Table 2. Log-normal regression of the time to recurrence, other-cause mortality and breast cancer death after recurrence

\begin{tabular}{|c|c|c|c|c|c|c|}
\hline \multirow{3}{*}{$\begin{array}{l}\text { From } \\
\text { To }\end{array}$} & \multicolumn{4}{|c|}{ Diagnosis } & \multirow{2}{*}{\multicolumn{2}{|c|}{$\begin{array}{c}\text { Recurrence } \\
\text { Breast cancer death }\end{array}$}} \\
\hline & \multicolumn{2}{|c|}{ Recurrence } & \multicolumn{2}{|c|}{ Other cause death } & & \\
\hline & Coefficient & $P>z$ & Coefficient & $P>z$ & Coefficient & $\mathbf{P}>\mathbf{z}$ \\
\hline $\begin{array}{l}\text { Low adherence }(<80 \%) \\
\text { Propensity score } \\
\text { Year of diagnosis }\end{array}$ & $\begin{array}{r}-0.5238 \\
-0.0948 \\
0.1108 \\
\end{array}$ & $\begin{array}{l}0.000 \\
0.241 \\
0.006\end{array}$ & $\begin{array}{r}-0.2314 \\
-0.0611 \\
0.0213\end{array}$ & $\begin{array}{l}0.055 \\
0.303 \\
0.501\end{array}$ & $\begin{array}{r}0.3349 \\
-0.1284 \\
0.0835\end{array}$ & $\begin{array}{l}0.161 \\
0.453 \\
0.207\end{array}$ \\
\hline \multicolumn{7}{|c|}{ Age group (reference $<60$ ), years } \\
\hline $\begin{array}{l}60-69 \\
70-79 \\
80+\end{array}$ & $\begin{array}{l}-1.6128 \\
-2.4296 \\
-3.6462 \\
\end{array}$ & $\begin{array}{l}0.206 \\
0.134 \\
0.103\end{array}$ & $\begin{array}{l}-1.8726 \\
-3.0279 \\
-3.7415\end{array}$ & $\begin{array}{l}0.048 \\
0.011 \\
0.022\end{array}$ & $\begin{array}{l}-1.7643 \\
-2.8490 \\
-4.3778\end{array}$ & $\begin{array}{l}0.444 \\
0.379 \\
0.218\end{array}$ \\
\hline \multicolumn{7}{|c|}{ Menopausal (reference pre/peri) } \\
\hline $\begin{array}{l}\text { Post } \\
\text { Unknown }\end{array}$ & $\begin{array}{r}-0.0378 \\
0.7762\end{array}$ & $\begin{array}{l}0.895 \\
0.078\end{array}$ & $\begin{array}{l}-4.2405 \\
-4.1833 \\
\end{array}$ & $\begin{array}{l}0.973 \\
0.973\end{array}$ & $\begin{array}{r}-0.1661 \\
0.2448 \\
\end{array}$ & $\begin{array}{l}0.721 \\
0.776\end{array}$ \\
\hline \multicolumn{7}{|c|}{ SIMD quintile (reference 1and 2: deprived) } \\
\hline $\begin{array}{l}\text { 3-5 (Affluent) } \\
\text { Unknown }\end{array}$ & $\begin{array}{r}0.2747 \\
-0.0725\end{array}$ & $\begin{array}{l}0.126 \\
0.924\end{array}$ & $\begin{array}{l}0.3055 \\
0.1819\end{array}$ & $\begin{array}{l}0.020 \\
0.754\end{array}$ & $\begin{array}{l}0.3970 \\
0.4298\end{array}$ & $\begin{array}{l}0.111 \\
0.682\end{array}$ \\
\hline \multicolumn{7}{|c|}{ Charlson's index (reference 0) } \\
\hline $\begin{array}{l}1-2 \\
3+\end{array}$ & $\begin{array}{l}-0.4042 \\
-0.2910 \\
\end{array}$ & $\begin{array}{l}0.142 \\
0.109\end{array}$ & $\begin{array}{l}-0.2352 \\
-0.0040\end{array}$ & $\begin{array}{l}0.226 \\
0.978\end{array}$ & $\begin{array}{r}-0.6477 \\
0.0973\end{array}$ & $\begin{array}{l}0.540 \\
0.781\end{array}$ \\
\hline \multicolumn{7}{|c|}{ Tumour stage (reference $1-2$ ) } \\
\hline $\begin{array}{l}3-4 \\
\text { Unknown }\end{array}$ & $\begin{array}{l}0.7033 \\
0.4318\end{array}$ & $\begin{array}{l}0.490 \\
0.360\end{array}$ & $\begin{array}{l}1.0442 \\
0.2477\end{array}$ & $\begin{array}{l}0.156 \\
0.456\end{array}$ & $\begin{array}{l}1.6068 \\
0.6810\end{array}$ & $\begin{array}{l}0.424 \\
0.346\end{array}$ \\
\hline \multicolumn{7}{|c|}{ Axillary nodes (reference 1 ) } \\
\hline $\begin{array}{l}\text { 2-3 } \\
\text { Unknown }\end{array}$ & $\begin{array}{l}-0.9710 \\
-1.2264 \\
\end{array}$ & $\begin{array}{l}0.000 \\
0.073\end{array}$ & $\begin{array}{r}0.2707 \\
-0.4661 \\
\end{array}$ & $\begin{array}{l}0.273 \\
0.313\end{array}$ & $\begin{array}{r}0.0615 \\
-0.7670 \\
\end{array}$ & $\begin{array}{l}0.839 \\
0.197\end{array}$ \\
\hline \multicolumn{7}{|c|}{ Metastases (reference no) } \\
\hline $\begin{array}{l}\text { Yes } \\
\text { Unknown }\end{array}$ & $\begin{array}{l}-0.8591 \\
-0.6088 \\
\end{array}$ & $\begin{array}{l}0.186 \\
0.238\end{array}$ & $\begin{array}{r}-0.3906 \\
0.0096 \\
\end{array}$ & $\begin{array}{l}0.415 \\
0.981\end{array}$ & $\begin{array}{r}0.0216 \\
-1.1175 \\
\end{array}$ & $\begin{array}{l}0.986 \\
0.260\end{array}$ \\
\hline \multicolumn{7}{|c|}{ Tumour grade (reference 1-2) } \\
\hline $\begin{array}{l}3 \\
\text { Unknown }\end{array}$ & $\begin{array}{l}-0.7219 \\
-0.0134 \\
\end{array}$ & $\begin{array}{l}0.000 \\
0.957\end{array}$ & $\begin{array}{l}0.0349 \\
0.0716\end{array}$ & $\begin{array}{l}0.839 \\
0.687\end{array}$ & $\begin{array}{l}-0.5842 \\
-0.1282\end{array}$ & $\begin{array}{l}0.144 \\
0.823\end{array}$ \\
\hline \multicolumn{7}{|c|}{ Oestrogen receptor status (reference negative) } \\
\hline $\begin{array}{l}\text { Positive } \\
\text { Unknown }\end{array}$ & $\begin{array}{l}-1.2131 \\
-0.8566\end{array}$ & $\begin{array}{l}0.384 \\
0.543\end{array}$ & $\begin{array}{l}-0.4607 \\
-0.7118\end{array}$ & $\begin{array}{l}0.642 \\
0.484\end{array}$ & $\begin{array}{l}-1.5521 \\
-1.4596\end{array}$ & $\begin{array}{l}0.579 \\
0.633\end{array}$ \\
\hline
\end{tabular}

patients incurred some medical costs in a certain follow-up year, their costs were higher if they were older at diagnosis $(P<0.001)$, living in a deprived area $(P=0.007)$, lower tumour stage $(P=0.025)$ or had node involvement $(P<0.001)$. The results suggested that the first follow-up year and follow-up years with recurrence or death had significantly higher costs. Patients with low adherence were $37.05 \%$ less likely to have any costs $(P<0.001)$, but once they had costs, these were expected to be $25.76 \%$ higher annually $(P<0.001)$.

Outcomes, costs and the value of adherence. The summary statistics of the Markov models in terms of health outcomes and costs of tamoxifen for high and low adherence are presented in Table 4. High adherence was estimated to reduce recurrence by
8.95\% (95\% CI: -11.01 to $-6.89 \%)$ and deaths from breast cancer by $8.65 \%$ (95\% CI: -10.69 to $-6.57 \%)$. High adherence was associated with expected further life years (LYs) of 14.78 and expected QALYs (discounted at 3.5\%) of 11.43 compared with low adherence with 13.35 and 10.31 , respectively.

Low adherence resulted in a loss of 1.43 LYs (95\% CI: 1.15-1.71) or 1.12 QALYs (95\% CI: 0.91-1.34). Over the expected lifetime, there was an incremental cost of $£ 5970$ for low vs high adherence (95\% CI: $-£ 7372$ to $-£ 4644$ ) mainly due to the difference in in-patient stay and other dispensing costs.

As expected, high adherence to tamoxifen dominated low adherence with $100 \%$ of simulations showing it was both more effective and less costly than low adherence. Assuming a willingness to pay adoption threshold of $£ 25000$ per QALY, the 
Table 3. Estimation results of the two-part models on annual medical costs

1. Logit (non-zero costs)

1. Logit (non-zero costs)

2. In (costs)

\begin{tabular}{|l|c|c|c|c|}
\hline & Coefficient & P> & Coefficient & P>t \\
\hline Low adherence (<80\%) & -0.4629 & 0.000 & 0.2576 & 0.000 \\
Propensity score & 0.0905 & 0.414 & 0.0868 & 0.026 \\
\hline
\end{tabular}

\section{Follow-ups (reference Yr2 +)}

\section{Yr1}

Local recurrence

Axiliary recurrence

Distant recurrence

Breast cancer death

Other-cause death

Year of diagnosis

\section{Age group (reference $<60$ ), years}

60-69

70-79

$80+$
1.6259
3.3071

3.5656
0.267

0.118

0.125
1.2613

2.1157

2.6093
0.016

0.004

0.001

Menopausal (reference pre/peri)

Post

Unknown

0.3164

$-0.1112$

0.082

0.838

0.1541

$-0.3070$

0.119

0.122

SIMD quintile (reference 1 and 2: deprived)

3-5- affluent

$-0.8081$

$-0.7696$

0.000

0.233

$-0.1402$

0.007

Charlson's index (reference 0)

$1-2$
$3+$

0.8782

0.3064

0.215

0.069

0.5497

0.0631

0.022

0.381

Tumour stage (reference 1-2)

3-4

Unknown

$-1.2306$

$-0.4610$

0.367

0.291

$-1.0324$

$-0.2107$

0.025

0.186

\section{Axillary nodes (reference 1)}

2-3

Unknown

0.2379

0.9024

0.218

0.007

0.3075

0.3007

0.000

0.031

Metastases (reference yes)

No

Unknown

$-15.5193$

$-15.6810$

0.022

0.012

$-0.5763$

$-0.1932$

0.075

0.444

Tumour grade (reference 1-2)

3

Unknown

$-0.3441$

$-0.2229$

0.160

0.470

$-0.0187$

$-0.0340$

0.840

0.780

Oestrogen receptor status (reference negative)

\begin{tabular}{|l|r}
\hline Positive & 1.6267
\end{tabular}

Unknown

$\%$ Missing months

1.6267
1.8644

$-1.0209$

0.360
0.341
0.000

1.1324

1.2796

$-0.0787$

0.073

0.066

0.180

Coefficients in the first column capture how the probability a patient have non-zero costs within a year post cancer changes with variables; and coefficients in the second column capture, for patients with any costs within a year, how the amount of costs changes with variables.

expected value or NMB of changing a patient from low adherence to high adherence was $£ 33897$ (95\% CI: $£ 28322-£ 39652$ ).

Sensitivity analysis. Where the difference in costs between high and low adherence was only contributed to a higher chance of recurrence or other death, the incremental discounted cost of low adherence reduced to $£ 1263$ (95\% CI: £204-£2361) and the NMB of high vs low adherence reduced to $£ 29161$ (95\% CI: £23 595-£34715). When an alternative discount rate of $1.5 \%$ for outcomes was used, the incremental discounted QALYs of high adherence increased to 1.66 QALYs (95\% CI: 1.32-2.00). The NMB equalled $£ 47501$ (95\% CI: $£ 38893, £ 56160)$ if low adherence patients were assigned with 
Table 4. Baseline and sensitivity analysis results for tamoxifen patients with high and low adherence

Adherence

\begin{tabular}{|l|l|l|l}
\hline & $\geqslant 80 \%$ & $<80 \%$ & Difference $(95 \% \mathrm{Cl})$
\end{tabular}

Baseline analysis $^{a}$ (Outcomes and costs discounted at $3.5 \%$ )

Events (\%)

Recurrence

Breast cancer death

$17.65 \%$

$17.32 \%$

$26.59 \%$

$25.97 \%$

$-8.94 \%(-11.01 \%,-6.89 \%)$

$-8.65 \%(-10.69 \%,-6.57 \%)$

Effects (average per patient)

LYs

OALYs

14.78

11.43

13.35

10.31

$1.43(1.15,1.71)$

$1.12(0.91,1.33)$

\section{Costs}

Tamoxifen dispensing

Inpatients and other dispensing

Total costs

$£ 100$

$£ 14747$

$£ 14847$

$£ 56$
$£ 20765$
$£ 20821$

$£ 44(£ 43, £ 45)$

$-£ 6014(-£ 7416,-£ 4688)$

$-£ 5970(-£ 7372,-£ 4644)$

\section{Cost-effectiveness ratio}

Cost per LY gained

Cost per QALY gained

NMB of high vs adherence at $£ 25000 / Q A L Y$

$-£ 4239(-£ 5583,-£ 3122)$

$-£ 5414(-£ 7143,-£ 3993)$

Sensitivity analysis (costs) ${ }^{\mathrm{b}}$ (Outcomes and costs discounted at $3.5 \%$ )

In-patients and other dispensing

Total costs

Cost per LY gained

Cost per QALY gained

NMB of high vs adherence at $£ 25000 / Q A L Y$

$£ 33897(£ 28322, £ 39652)$

Sensitivity analysis (effects) (Outcomes discounted at $1.5 \%$ and costs at $3.5 \%$ )

LYS

QALYs

Cost per LY gained ${ }^{a}$

Cost per QALY gained ${ }^{a}$

NMB of high vs adherence at $£ 25000 /$ QALY $^{a}$

Cost per LY gained ${ }^{\mathbf{b}}$

Cost per QALY gained ${ }^{\mathbf{b}}$

NMB of high vs adherence at $£ 25000 /$ OALY $^{b}$
$£ 16056$

$£ 16112$
$-£ 1307(-£ 2405,-£ 247)$

$-£ 1263(-£ 2361,-£ 204)$

$-£ 894(-£ 1700,-£ 145)$

$-£ 1142(-£ 2172,-£ 185)$

Abbreviations: $\mathrm{LY}=$ life year; $\mathrm{NMB}=$ net monetary benefit; $\mathrm{QALY}=$ quality-adjusted life year

${ }^{a}$ Assume annual costs of in-patients and other dispensing differ between high-adherence and low-adherence patients.

${ }^{\mathbf{b}}$ Assume low-adherence patients bear the same annual costs of in-patients and other dispensing as high-adherence patients (predictions are made based on high-adherence patients).

different annual costs and £42861 (95\% CI: £34550, £51266) otherwise. The results were robust with high adherence dominating in at least $95 \%$ of simulations throughout all sensitivity analyses.

\section{DISCUSSION}

Within 5 years from diagnosis, approximately two-fifths of women prescribed tamoxifen had adherence less than $80 \%$, which was associated with significantly shorter time to recurrence and significantly higher health service costs, once costs were incurred. Assuming the current value of a QALY is $£ 25000$, the expected value of changing a patient from low to high adherence was $£ 33897$ (95\% CI: £28 322-£39 652).
This study provides empirical evidence, which suggest the importance of improving adherence to adjuvant tamoxifen in community settings and also indicates the potential benefits of investing in adherence to enhance health outcomes and economic efficiency.

Furthermore, we demonstrate that younger patients were more likely to have lower adherence, whereas the patients' tumour stage and status of ER are also significantly associated with adherence behaviour.

Comparison to the literature. This study supports published literature showing that a large proportion of women have low adherence over the 5 years following diagnosis (Barron et al, 2007; Ma et al, 2008; McCowan et al, 2008; Owusu et al, 2008; Yood et al, 2008; Narod, 2010; van Herk-Sukel et al, 2010; Hershman et al, 
2011; Murphy et al, 2012; Hadji et al, 2013; Huiart et al, 2013; Makubate et al, 2013). For those women with low adherence, there is an increased risk of poor health outcomes, although the association with other-cause mortality was not significant (Patridge et al, 2003; McCowan et al, 2008; Dezentje et al, 2010; Hershman et al, 2010, 2011; Makubate et al, 2013).

Although no previous studies were identified that had performed an economic analysis of adherence to tamoxifen, the finding that low adherence was associated with higher costs and lower quality of life fits well with the studies reporting the costeffectiveness of tamoxifen use (Glasziou and Haas, 1994; Yang et al, 2010). We report a higher difference of QALYs than the original Australian study, but have confirmed the direction of effect with our increased difference possibly due to differences in the underlying populations and groupings within the two studies. The findings also relate well to a study of the cost-effectiveness of statins, which reported that improving adherence to medication would enhance cost-effectiveness (Greving et al, 2011).

This study provides direct evidence that low adherence to longterm oral breast cancer therapy results in poor health outcomes and increased health costs. This has become a growing concern as shown by the calls to develop interventions that improve adherence, as such interventions might have a greater impact on population health than improvements in specific medical treatments (Sabaté and World Health Organization, 2003).

Implications for practice. The adherence behaviour of patients is a complex process determined by many factors (Osterberg and Blaschke, 2005; Ruddy et al, 2009). Besides patient-related factors, the characteristics of the disease and its treatment, the attributes of the health-care system and service delivery may also influence adherence (Murphy et al, 2012; Hadji et al, 2013). It may be difficult to identify patients who will have low adherence until that behaviour is established and it is also likely that no single approach will be successful. There is a need for studies on the design of interventions that improve adherence more effectively (Sabaté and World Health Organization, 2003; Murphy et al, 2012). Clinicians currently supporting women receiving adjuvant therapy for breast cancer should specifically ask about adherence and increase the support they offer to encourage more women to complete their full course of medication.

Strengths and limitations. The study was based on women managed within the community and used actual health service resource use allocation to inform the economic evaluation. The initial population comprised all breast cancers diagnosed from an entire population with exclusions based on well-described criteria. Although measuring adherence to medication is complex, we used an established method. The dispensed prescribing records were from a closed prescribing system with every prescription presented to a pharmacist recorded and collated and these data were then linked to health board wide population databases including cancer registry and official death certificates.

We applied a propensity score method to reduce the potential selection bias of low adherence when modelling health outcomes and medical costs: patients who have low adherence to tamoxifen may have poor health prospects, and in addition, they may prefer to use less health resources, which may induce more health-care costs later on when their condition worsens. However, a sensitivity analysis reported consistent results when low-adherence patients were assigned with the same predictions on other annual costs as if they had high adherence.

We excluded a 60-day period before death or recurrence in our calculations of adherence to allow for the possibility that patients may stop taking medications as they approached either. A longer exclusion period may modify the results but we felt that a twomonth window was a sufficient period. Our adherence measure included women with poor persistence who had stopped taking medication before completing a 5-year course or having a recurrence or death. Our study numbers are insufficient to disentangle whether patient who take drugs regularly but for a shorter period than recommended have different outcomes from those who take the drugs for longer periods of time but at less regular intervals. However, our focus was on whether adherence to recommended treatment improved patient and economic outcomes. We used data from a Swedish population to estimate QALYs, as this was the most reliable data available for our study and also represents a similar, predominantly Caucasian population in a socialised health-care system (Lidgren et al, 2007). Our use of an average cost for prescriptions other than tamoxifen when estimating patient costs has limitations, but as we would have been unable to attribute which medications were used specifically for breast cancer or associated conditions, we felt this was a suitable assumption within our study.

Our focus was limited to adherence in tamoxifen patients given the sampling period and duration of follow up. A further evaluation comparing the impact of adherence to AIs compared with tamoxifen adjuvant endocrine therapy is necessary. However, such analyses should be confined to post-menopausal women, whereas the current study examined women of all ages. As evidence emerges for the long-term benefits of adjuvant tamoxifen beyond 5 years, specifically the trials comparing 10 years $v s 5$ years adjuvant tamoxifen (and similar duration trials for AIs), the issues around adherence will become even more critical for the long-term health and economic impacts of breast cancer therapy.

\section{CONCLUSION}

The consequences of low adherence to tamoxifen are poorer health outcomes, increased health-care costs and worse quality of life. Interventions that encourage patients to continue taking their treatment on a daily basis for the recommended 5-year period should improve outcomes and may be highly cost-effective, with the investment justified by better health outcomes and savings in reduced health-care utilisation.

\section{ACKNOWLEDGEMENTS}

We thank the Health Informatics Centre, University of Dundee, for anonymisation, record linkage and other procedural assistance in preparing the data set. The study was funded by Breast Cancer Campaign (Grant 2008NovPR01). All data were fully anonymised and data use was compliant with the Health Informatics Centre research governance process, which are approved by the Tayside Committee on Medical Research Ethics and the Caldicott Guardian.

\section{CONFLICT OF INTEREST}

All authors have completed the ICMJE uniform disclosure form at www.icmje.org/coi_disclosure.pdf; the authors declare no conflict of interest.

\section{AUTHOR CONTRIBUTIONS}

CMcC and AMT conceived the study and supported DJP and SW who planned the study. SW carried out the analysis with support from DJP, BM and CMcC. All authors contributed to the writing of the paper. $\mathrm{CMcC}$ is the guarantor. 


\section{REFERENCES}

Appleby J, Devlin N, Parkin D (2007) NICE's cost effectiveness threshold. BMJ 335(7616): 358-359.

Barron TI, Connolly R, Bennett K, Feely J, Kennedy MJ (2007) Early discontinuation of tamoxifen. Cancer 109(5): 832-839.

Burnham KP, Anderson DR (2004) Multimodel Inference: Understanding AIC and BIC in Model Selection. Sociol Methods Res 33(2): 261-304.

Delea T, Karnon J, Sofrygin O, Thomas S, Papo N, Barghout V (2007) Cost-effectiveness of letrozole versus tamoxifen as initial adjuvant therapy in hormone receptor-positive postmenopausal women with early-stage breast cancer. Clin Breast Cancer 7(8): 608-618.

Deyo RA, Cherkin DC, Ciol MA (1992) Adapting a clinical comorbidity index for use with ICD-9-CM administrative databases. J Clin Epidemiol 45(6) 613-619.

Dezentje VO, van Blijderveen NJC, Gelderblom H, Putter H, van Herk-Sukel MPP, Casparie MK, Egberts ACG, Nortier JWR, Guchelaar H-J (2010) Effect of concomitant CYP2D6 inhibitor use and tamoxifen adherence on breast cancer recurrence in early-stage breast cancer. J Clin Oncol 28(14): 2423-2429.

Early Breast Cancer Trialists' Collaborative Group (2011) Relevance of breast cancer hormone receptors and other factors to the efficacy of adjuvant tamoxifen: patient-level meta-analysis of randomised trials. Lancet 378(9793): 771-784.

Glasziou P, Haas M (1994) An Economic Evaluation of the Use of Tamoxifen in the Treatment of Early Breast Cancer. CHERE, University of Technology: Sydney.

Greving J, Visseren F, Gd Wit, Algra A (2011) Statin treatment for primary prevention of vascular disease: whom to treat? Cost-effectiveness analysis. BMJ 342: d1672.

Hadji P, Ziller V, Kyvernitakis J, Bauer M, Haas G, Schmidt N, Kostev K (2013) Persistence in patients with breast cancer treated with tamoxifen or aromatase inhibitors: a retrospective database analysis. Breast Cancer Res Treat 138(1): 185-191.

Hershman D, Shao T, Kushi L, Buono D, Tsai W, Fehrenbacher L, Kwan M, Gomez S, Neugut A (2011) Early discontinuation and non-adherence to adjuvant hormonal therapy are associated with increased mortality in women with breast cancer. Breast Cancer Res Treat 126(2): 529-537.

Hershman DL, Kushi LH, Shao T, Buono D, Kershenbaum A, Tsai W-Y, Fehrenbacher L, Lin Gomez S, Miles S, Neugut AI (2010) Early discontinuation and nonadherence to adjuvant hormonal therapy in a cohort of 8769 early-stage breast cancer patients. J Clin Oncol 28(27): $4120-4128$

Huiart L, Ferdynus C, Giorgi R (2013) A meta-regression analysis of the available data on adherence to adjuvant hormonal therapy in breast cancer: summarizing the data for clinicians. Breast Cancer Res Treat 138(1): 325-328.

Indurkhya A, Mitra N, Schrag D (2006) Using propensity scores to estimate the cost-effectiveness of medical therapies. Stat Med 25(9): 1561-1576.

ISD Scotland, Scottish Government (2012a) Costs: Finance (online). Available at http://www.isdscotland.org/Health-Topics/Finance/Costs/ (accessed 29 January 2013).

ISD Scotland, Scottish Government (2012b) Community dispensing: Prescription Cost Analysis (online) Available at www.isdscotland.org/ Health-Topics/Prescribing-and-Medicines/Community-Dispensing/ Prescription-Cost-Analysis/ (accessed 29 January 2013).

Lidgren M, Wilking N, Jönsson B, Rehnberg C (2007) Health related quality of life in different states of breast cancer. Qual Life Res 16(6): 1073-1081.

Ma AMT, Barone J, Wallis AE, Wu NJ, Garcia LB, Estabrook A, RosenbaumSmith SM, Tartter PI (2008) Noncompliance with adjuvant radiation, chemotherapy, or hormonal therapy in breast cancer patients. Am J Surg 196(4): 500-504.

Makubate B, Donnan PT, Dewar JA, Thompson AM, McCowan C (2013) Cohort study of adherence to adjuvant endocrine therapy, breast cancer recurrence and mortality. Br J Cancer 108(7): 1515-1524.

McCowan C, Shearer J, Donnan PT, Dewar JA, Crilly M, Thompson AM, Fahey TP (2008) Cohort study examining tamoxifen adherence and its relationship to mortality in women with breast cancer. Br J Cancer 99(11): $1763-1768$.

McDonald HP, Garg AX, Haynes RB (2002) Interventions to enhance patient adherence to medication prescriptions JAMA 288(22): 2868-2879.

Murphy C, Bartholomew LK, Carpentier M, Bluethmann S, Vernon S (2012) Adherence to adjuvant hormonal therapy among breast cancer survivors in clinical practice: a systematic review. Breast Cancer Res Treat 134(2): $459-478$.

Murthy V, Bharia G, Sarin R, Murthy V, Bharia G, Sarin R (2002) Tamoxifen non-compliance: does it matter? Lancet Oncol 3(11): 654.

Narod SA (2010) Compliance With Tamoxifen in Women With Breast Cancer and a BRCA1 or BRCA2 Mutation. J Clin Oncol 28(33): e698-e699.

National Institute for Health and Clinical Excellence (2011) Discounting of health benefits in special circumstances (online). Available at http://www. nice.org.uk/media/955/4F/Clarification_to_section_5.6_of_the_Guide_to_ Methods_of_Technology_Appraisals.pdf (accessed 29 January 2013).

Osterberg L, Blaschke T (2005) Adherence to Medication. N Engl J Med 353(5): 487-497.

Owusu C, Buist DS, Field TS, Lash TL, Thwin SS, Geiger AM, Quinn VP, Frost F, Prout M, Yood MU, Wei F, Silliman RA, Owusu C, Buist DSM, Field TS, Lash TL, Thwin SS, Geiger AM, Quinn VP, Frost F, Prout M, Yood MU, Wei F, Silliman RA (2008) Predictors of tamoxifen discontinuation among older women with estrogen receptor-positive breast cancer. J Clin Oncol 26(4): 549-555.

Palisade. @Risk 5.7 (2009) Ithaca NY: Palisade Corporation.

Patridge A, Wang P, Winer E, Avorn J (2003) Nonadherence to adjuvant tamoxifen therapy in women with primary breast cancer. J Clin Oncol 21(4): 602-606.

Royston P (2004) Multiple imputation of missing values. Stata J 4: 227-241.

Ruddy K, Mayer E, Partridge A (2009) Patient adherence and persistence with oral anticancer treatment. CA Cancer J Clin 59(1): 56-66.

Sabaté E. World Health Organization (2003) Adherence to long-term therapies: evidence for action (online). Available at http://www.who.int/ chp/knowledge/publications/adherence_report/en/ (accessed 29 January 2013).

Scottish Government (2012) Scottish index of multiple deprivation (online). Available at http://www.scotland.gov.uk/Topics/Statistics/SIMD (accessed 29 January 2013).

Scottish Intercollegiate Guideline Network Guidelines (2005) Breast Cancer in Women: A National Clinical Guideline. Scottish Intercollegiate Guideline Network: Edinburgh.

Sundararajan V, Henderson T, Perry C, Muggivan A, Quan H, Ghali WA (2004) New ICD-10 version of the Charlson comorbidity index predicted in-hospital mortality. J Clin Epidemiol 57(12): 1288-1294.

Van Buuren S, Boshuizen HC, Knook DL (1999) Multiple imputation of missing blood pressure covariates in survival analysis. Stat Med 18(6): 681-694.

van Herk-Sukel M, van de Poll-Franse L, Voogd A, Nieuwenhuijzen G, Coebergh J, Herings R (2010) Half of breast cancer patients discontinue tamoxifen and any endocrine treatment before the end of the recommended treatment period of 5 years: a population-based analysis. Breast Cancer Res Treat 122(3): 843-851.

Yang JJ, Park SK, Cho LY, Han W, Park B, Kim H, Lee KS, Hahn SK, Cho SI, Ahn SH, Noh DY. Korean Breast Cancer S (2010) Cost-effectiveness analysis of 5 years of postoperative adjuvant tamoxifen therapy for Korean women with breast cancer: retrospective cohort study of the Korean breast cancer society database. Clin Ther 32(6): 1122-1138.

Yood MU, Owusu C, Buist DS, Geiger AM, Field TS, Thwin SS, Lash TL, Prout MN, Wei F, Quinn VP, Frost FJ, Silliman RA, Yood MU, Owusu C, Buist DSM, Geiger AM, Field TS, Thwin SS, Lash TL, Prout MN, Wei F, Quinn VP, Frost FJ, Silliman RA (2008) Mortality impact of less-than-standard therapy in older breast cancer patients. J Am Coll Surg 206(1): 66-75.

This work is published under the standard license to publish agreement. After 12 months the work will become freely available and the license terms will switch to a Creative Commons AttributionNonCommercial-Share Alike 3.0 Unported License. 